\title{
Creating a software to promote understanding about narrative in children with autism: reflecting on the design of feedback and opportunities to reason
}

\author{
Megan Davis ${ }^{+}$, Nuno Otero ${ }^{+}$, Kerstin Dautenhahn ${ }^{+}$, Chrystopher L. Nehaniv ${ }^{+}$, and Stuart D. Powell* \\ University of Hertfordshire \\ ${ }^{+}$Adaptive Systems Research Group, School of Computer Science \\ "School of Education \\ Hatfield, Hertfordshire, AL10 9AB, UK \\ \{m.davis, n.r.otero, k.dautenhahn, c.l.nehaniv, s.d.powell\}@herts.ac.uk
}

\begin{abstract}
TouchStory is a software game that aims at improving the understanding of narrative by children with autism. In fact, the underlying conceptual framework intends to investigate to what extent we can improve the children's understanding of narrative through the introduction of simple game-like tasks that address primitive components of narrative.

The game has strong analogies with the concrete, physical world. Our design approach, following our knowledge regarding this particular group of learners, was to 'keep things simple', introducing features only if necessary to provide each individual child with a focussed and enjoyable game, from which that particular child may learn about, or absorb, (or become more familiar with) primitive components of narrative. In this paper we concentrate on issues of reward, feedback, and opportunities for reasoning (about the task and/or their own performance) provided by software. We present results from the first 7 visits of an ongoing longitudinal study involving 6 children each with a diagnosis of autism. We consider the children's apparent engagement with TouchStory, and in particular, we focus on the strategy each child adopts and consequent feedback from the software. This analysis prompted us to further reflect on the specificities of this group of children and the challenges to create supportive learning environments.
\end{abstract} design

Index Terms - Autism, narrative, interaction, software

\section{INTRODUCTION}

The central importance of narrative in shaping human culture, social relations and experience is widely acknowledged. By fitting events, particularly surprising events, into a narrative structure, human beings inhabit largely meaningful inner and social worlds $[1,2]$.

Autism is a lifelong pervasive developmental disorder affecting social understanding and interaction. Research has shown a deficit in the comprehension and creation of narrative in children with autism [3-5] adversely impacting their social skills.

The present paper presents TouchStory: a picture-based software game developed specifically for children with autism that aims at improving their understanding of narrative. Our underlying conceptual framework intends to investigate to what extent we can improve the understanding individual children with autism have of narrative through the introduction of simple picture-based tasks that address primitive components of narrative. A previous study of 12 visits involving 12 children (10 with autism) found a correlation between TouchStory results and a real-world picture-narrative comprehension task. Additionally, results showed a clearly differentiated understanding of the various primitive components of narrative [6]. These results encourage us to believe that TouchStory has real world relevance.

A new, currently ongoing, study, using new participants, has been designed to investigate whether children's performance with TouchStory improves over time, and where so, whether increased understanding is also observed in the real world. In this paper, drawing data from the first 7 visits of the new study, we consider the children's apparent engagement with TouchStory. In particular we focus on the strategy each child adopts and the feedback, and consequently the learning opportunities, provided by the software in response to the strategies used. While our focus in this paper is on detailed interaction with TouchStory, the development of TouchStory inscribes itself in our overarching goal of investigating ways to improve the children's understanding of everyday social situations, and hence their general wellbeing.

Computer artifacts for children with autism: Researchers have shown that the simple, predictable and controllable behaviours of computers and robots are particularly suitable for children with autism [7]. However, although it as an area of increasing research interest, there is still little software written specifically for children with autism. A conversational agent as an authorable virtual peer promoting social stories for high functioning children with autism is described in [8]; social stories are exemplars of what to do in certain social situations, for example a child may be given a social story about what to do at playtime. Massaro [9] describes an embodied agent and story telling techniques used with children with language challenges, including children with autism; the focus is on improving language. These differ from the current study which aims at promoting an understanding of narrative structure per se. A fuller treatment of related studies is given in [6]. 


\section{THE DESIGN OF TOUChSTORY}

Design guidelines concerning learning environments for children with autism: People with autism form a diverse group; however, there are commonalities which may be taken into account when designing software. People with autism all exhibit impaired social interaction and communication, and have a limited range of imaginative activities [10-12]. Additionally it is common to find particular sensitivities [13], repetitive behaviour patterns, resistance to change in routine [14], and difficulties in sequencing events [15].

Jordan and Powell advise that a learning environment for children with autism, should be as dependable and predictable as possible, with any required unpredictability carefully introduced in a controlled way [16]. They advise that the learning activities should be challenging, but children should not be penalised for mistakes as they may be using strategies which worked in the past, and the fact that they do not work in the current situation can be very debilitating. Feedback on failure should be non-threatening and must be accompanied by clear cues to an alternative way forward. Lastly they advise that children should be allowed time to enjoy their mastery of a skill before moving on [16]. The following design issues were specifically considered in our work:

- Children with autism are generally are highly visual. Design solution: The narratives and proto-narratives are presented as pictures, with no verbal commands.

- They tend to employ local rather than global integration [17]; a child with autism might focus exclusively on some seemingly irrelevant detail. Design solution: The screen design was kept very simple with no extraneous features such as sounds or animations.

- They may be highly sensitive to noise, finding intolerable noise which is barely perceptible or unremarkable to others [13]. Design solution: No sound features are used in the game.

- They generally enjoy repetition. Design solution: TouchStory relies on the sequential aspect of playing the game with some aspects of repetition which is meant to provide a comfortable environment for the children.

- They may enjoy repetition to the detriment of other activities. Design solution: An autonomy/control balance was aimed for; e.g. children who were able could use a 'next' button to move on to the next t-story (explained below). However repeated pressing of the 'next' button had no effect. Additionally, there are no features whose purpose is solely to attract and maintain attention.

- They may have problems with manual dexterity. Design solution: A simple docking function aids the final placement of the child's chosen answer.

- They may find failure very debilitating [16] Design solution: There is no penalty for a wrong answer. The accompanying adult may encourage another attempt if appropriate to the particular child at the time.
Conceptual and design issues behind the development of t-stories: Our intention was to investigate 'primitive' elements of narrative (proto-narratives) as a precursor of narrative comprehension. We identified these as the characters, the settings or background, and the sequence of events of the narrative. Further, we argue that a narrative sequence is a special form of temporal sequence therefore we include both temporal sequences and sequences with no temporal dimension which we call reversible sequences. We introduce the term $\boldsymbol{t}$-story to mean picture narratives and proto-narratives collectively, and in contrast to fully developed complex stories; $t$-stories were prepared for each primitive type. A reversible sequence t-story is shown in Fig 1. The pictures in the lower row are draggable and can be moved over the screen with a finger. The game is to dock the correct picture from the lower row into the gap in the upper t-story panel (this we call the $t s$-gap). As the pictures are draggable it is possible to move a picture close to the ts-gap as part of the decision making process, shown in Fig 2. The reward for a correct answer is that the bottom row disappears leaving just the completed answer, shown in Fig 4. Thus the reward reinforces the task, and exposes the child to more examples of proto-narrative sequences. There is no penalty for a wrong answer, illustrated in Fig 3, the player may try again, or move onto the next t-story. After the last t-story has been presented a screen shows the words 'Thank You' to signal the end of the game.

Conceptual and design issues behind the development of t-stories: Luc Steels discusses issues of fun and flow in learning environments in [18]. We describe how we address his specific points below:

- '.....the activity itself must be challenging - otherwise there is no feeling of satisfaction after difficulties have been surmounted. Moreover there must be a steady progression in the nature and particularly the level of the challenge.' In later stages the profile of t-stories shown is adapted to each individual child.

- To provide this in a learning environment: 'A learner must be able to feel some control of the challenge level,..' A child can accept or reject a challenge. For example after a wrong answer she may try again, or move on to the next t-story.

- ...'but at the same time the environment is crucial in generating new opportunities' New opportunities are provided by the rolling introduction of new t-stories (about $30 \%$ are replaced every second visit) and by the adaptation previously mentioned.

- $\quad . .$. ' and providing structure to the learning experience.' Structure is provided by consistency within the game: the basic task in each t-story is the same (fill the gap), the number of options is constant, and the TouchStory game is a linear sequence of t-stories. 


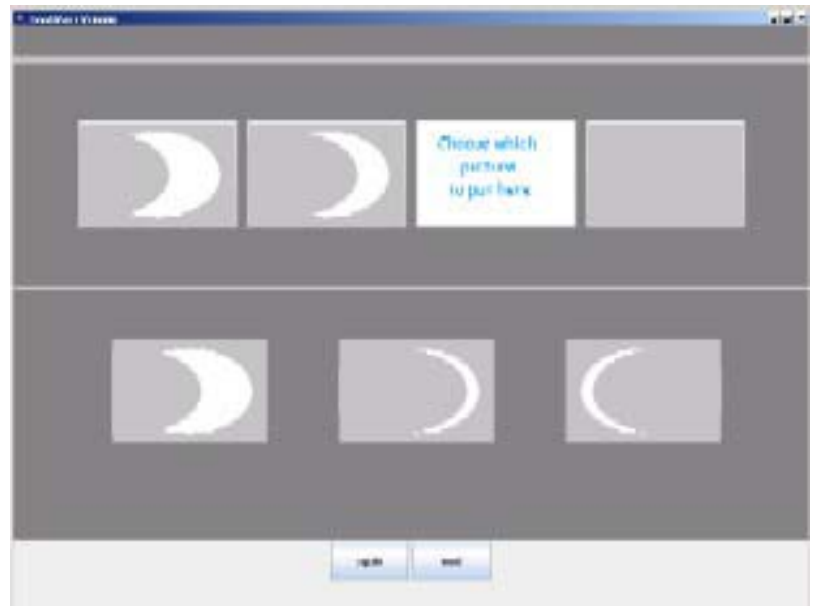

Fig. 1 A t-story in the initial state.

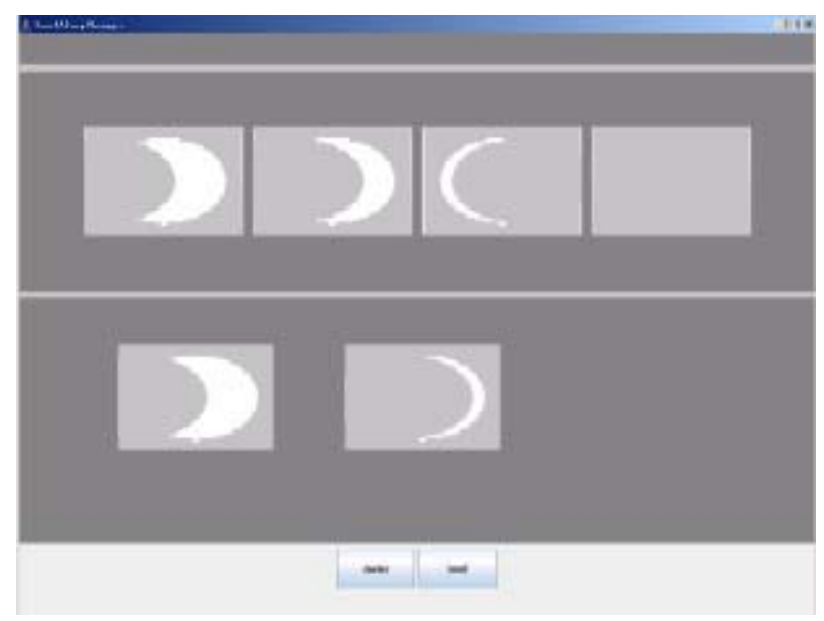

Fig. 3 The feedback for a wrong answer

\section{THE STUDY}

Methods of inquiry: The constructionist view of narrative comprehension predicts that each narratee will make inferences which establish both local and global coherence, and explain events and motivations [19]. However, the characteristics of autism make merely asking for such explanations problematic: some children with autism do not have productive language; those who do speak may choose not to answer (they may 'block out' unwanted questions by singing, reciting, or merely 'being absent'); children with autism have particular difficulty with 'why' and 'how' questions; and they have difficulty with social interaction. Thus, we prefer observational methods of inquiry; these include videotaping sessions and software data logging. To provide context we ask the school to complete a short questionnaire and provide a thumbnail sketch of each child. This study took place over seven visits. Approximately 15 t-stories were presented at each visit. Every alternate (odd numbered) visit approximately $30 \%$ of the t-stories was

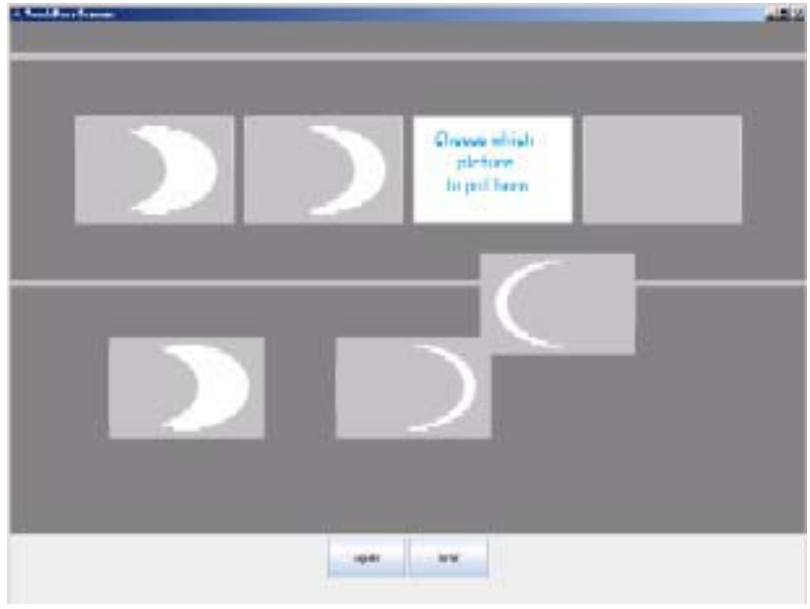

Fig 2 A game in play

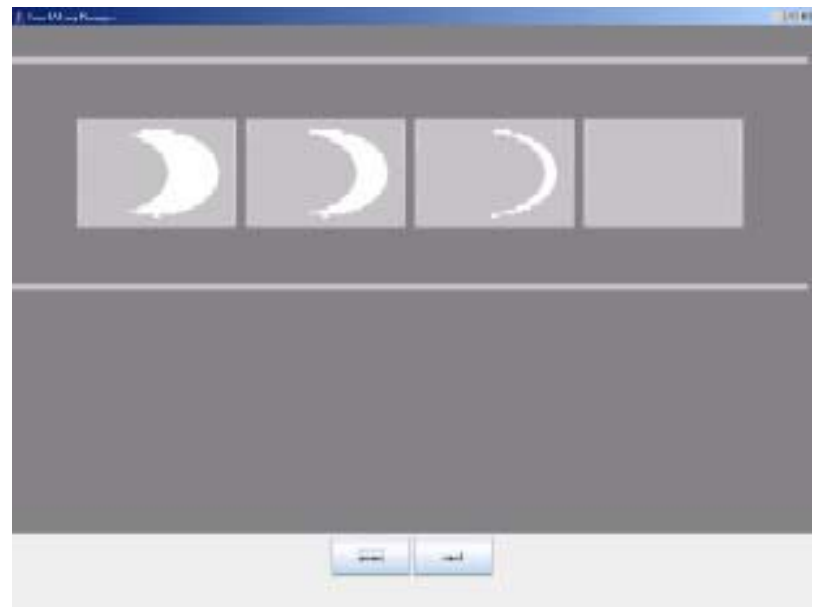

Fig. 4 The feedback for a correct answer

replaced by new previously unseen t-stories. Thus if a child learns or memorises the correct answer to specific t-stories from experience with TouchStory we should see an improvement between odd and even numbered visits, for example, they should score better in visit 4 than in visit 3 . If the child is also able to generalise then we should also notice an improvement over successive odd numbered visits, in which new t-stories are introduced.

Conduct of the study:This study was part of a longer study involving 6 children (5 boys, 1 girl), between the ages of 7 and 9 years, all with a diagnosis of autism, from a school for children with moderate learning difficulties in the south east of England. Three of the children were from a base within the school dedicated to children with autism, and three were integrated into general classes of about 9 children. The study was carried out in a caring and ecologically valid manner, attending adults gave praise and suggestions as they normally would, and, if appropriate, sessions would be abandoned at any point in the best interests of the child. The study took 
place in a small dedicated room close to the children's classrooms. At the beginning of the study a carer was present in addition to the experimenter, if appropriate to the particular child, for this particular activity. As the study progressed each child became confident and able to attend without a carer. In each session, a child skilled in manipulating the touch screen and confident of her answers could complete a set of t-stories in 2 minutes or less. A child spending more time thinking or manipulating the images on the screen might take up to 10 minutes.

Introducing distracters to tap into children's level of engagement: We do not expect boredom per se to be an issue for children with autism; the previous study [6] showed no decrease in apparent engagement over twelve visits, indeed some children appeared to become more engaged, for example more focussed on getting the right answer. However in that study there was no active attempt to distract the children from TouchStory. In the current study distractions were put in place in visit 6 . First, a small attractive colourful toy and a colourful attractive book were left near the touch screen prior to the child's session with TouchStory. Second, attempts were made to distract the child while the TouchStory game was in progress, by asking, 'Why did you choose that one?' Our prediction was that, unless distractions were in the child's area of special interest, the expected routine activity, in this case TouchStory, would be preferred.

\section{RESULTS}

Presentation of results The distractions put in place in visit 6 were mostly ignored by the children. One child noticed the toy, picked it up and played with it enthusiastically. He was easily refocused, with 'would you like to play with TouchStory now?' He made an enthusiastic 'Yeah' and abandoned the toy. Another child noticed the book and picked it up, but quickly put it down to play with TouchStory. The attempted interruptions while the TouchStory game was in progress elicited no response at all from 5 of the 6 children, they remained focussed on the game. One child did respond when 'Why did you choose that one?' had been asked several times with 'because it was right'.

In relation to behaviour displayed by the children while actively engaged in the interactions with TouchStory, we particularly focus the analysis at two points. The first point concerns the moment when the child has to choose which of the three images to dock (see Fig. 1 and Fig. 2). The second moment occurs if and when the child docks an image which is wrong; the feedback at this point is shown in Fig. 3. These findings are presented in Table 1 together with a thumbnail sketch of each child to provide context. We present the number of t-stories answered correctly by each child at each visit in Table 2.

Discussion of results: The results regarding the introduction of distracters strongly suggest that these were not disruptive. Only one child momentarily was distracted but was back on track easily. So, the question is not whether a child can be persuaded to use TouchStory (recall that these children may have powerful avoidance techniques), but whether they are engaged with TouchStory in the intended way. If one considers the whole activity with TouchStory, it seems plausible to assume that the software offers the following opportunities for reason, reflection and choice:

- when a new t-story is presented the child has the opportunity to reason about the current t-story and its relationships with previous t-stories,

- when an answer is docked there is the opportunity to reflect on the chosen answer in order to abstract the principle that underlies,

- $\quad$ in the case of a wrong answer there is the opportunity to repeat this cycle and reflect on the possibilities,

- or just choose to move forward to the next t-story, possibly because the current t-story is not considered "interesting".

As stated in the previous section, we chose to concentrate our efforts in analysing two particular moments where visible actions from the children are available; when the children need to choose which image to dock, and what happens when feedback regarding an incorrect answer is given.

We consider first Child $\mathrm{C}$ who appeared actively engaged in getting the right answer at first attempt, and to understand the given feedback. In visit 1 , in each case where a wrong image was docked he moved it out of the way and made another selection. In all but one case he was correct with his second selection. He was still actively engaged at visit 7 . His results show evidence for improvement in performance with both familiar and unfamiliar t-stories, with a distinctive 'sawtooth' graph.

Child E was less successful than Child $\mathrm{C}$ at first attempt. She actively selected her first choice of image to dock (although she preferred the middle position), and she would reconsider a wrong answer and try again, in visit 1 on two occasions, both picture narratives, she selected again, for the remaining 6 wrong answers she moved straight on to the next t-story. There is some evidence that she was learning correct answers (performance in visit 6 is better than in visit 5, and performance in visit 4 is better than in visit 3) and possibly improving overall.

Child $\mathrm{H}$ was very successful at first attempt. He was keen to succeed and commented to the experimenter e.g. 'I got 15 today', 'or 'I wonder whether I will get 16 today'. (Note the children were not told or shown the number of t-stories offered or answered correctly at a visit, he was keeping track himself). When wrong he selected another option, and learned the right answer from this. However there is one t-story for which he did not, and instead, he always moved straight on to the next t-story. This then is an interesting conflict of behaviours.

Child $\mathrm{N}$ appeared actively engaged at both points; he was possibly improving very gradually. His difficulty was with temporal sequences. 
TABLE 1

STRATEGIES ADOPTED BY INDIVIDUAL CHILDREN WHEN A NEW T-STORY IS PRESENTED AND WHEN AN ANSWER IS DOCKED

\begin{tabular}{|c|c|c|}
\hline CHILD (with thumbnail sketches) & INITIAL IMAGE SELECTION & STRATEGY WHEN WRONG \\
\hline $\begin{array}{l}\text { Child C, a very withdrawn child who likes } \\
\text { computers. He does not like stories, and does not } \\
\text { tell them. He does not seem to understand the } \\
\text { motives or emotions of character in stories. } \\
\text { He will give an ear-piercing scream if asked to do } \\
\text { something he does not want to do. }\end{array}$ & $\begin{array}{l}\text { He appears actively engaged in getting the 'right } \\
\text { answer' at first docking. Having selected an image } \\
\text { he occasionally reconsiders and makes another } \\
\text { selection before docking. }\end{array}$ & $\begin{array}{l}\text { In almost all cases he selects and docks another } \\
\text { image. He usually moves the 'wrong' image away } \\
\text { from the dock zone, prior to making his second } \\
\text { selection. }\end{array}$ \\
\hline $\begin{array}{l}\text { Child E likes computers and a range of stories. May } \\
\text { understand basic emotions such as sad and happy, } \\
\text { and will retell known stories. }\end{array}$ & $\begin{array}{l}\text { This child also chooses answers from all three } \\
\text { positions, but favours the middle position, choosing } \\
\text { that for over half the answers. }\end{array}$ & $\begin{array}{l}\text { This child's strategy when the initial selection was } \\
\text { wrong was to select and dock another image. In } \\
\text { visit } 3 \text { this happened on every occasion. }\end{array}$ \\
\hline $\begin{array}{l}\text { Child H, like computers. He likes strange and } \\
\text { spooky stories and will retell simple stories he has } \\
\text { seen on TV programmes or computer games. He } \\
\text { sometimes seems to understand emotions and } \\
\text { motives of characters. }\end{array}$ & $\begin{array}{l}\text { This child actively chooses from the available } \\
\text { answers. }\end{array}$ & $\begin{array}{l}\text { This child used a variety of strategies: consider visit } \\
5 \text {; for } 2 \text { of the t-stories (types background and } \\
\text { temporal sequence) he selected and docked a } \\
\text { second option-these were both answered correctly } \\
\text { on the subsequent visit, but for the third (type } \\
\text { narrative sequence) he moved straight on to the } \\
\text { next t-story without a second attempt, and this } \\
\text { t-story was answered incorrectly again on the } \\
\text { subsequent visit. }\end{array}$ \\
\hline $\begin{array}{l}\text { Child } \mathrm{N} \text { likes computers and space or fantasy } \\
\text { stories. He does not understand the emotions or } \\
\text { motives of the characters. He will retell stories he } \\
\text { has already heard. }\end{array}$ & $\begin{array}{l}\text { This child actively selects from the available } \\
\text { images. Having selected an image he occasionally } \\
\text { reconsiders and makes another selection before } \\
\text { docking. }\end{array}$ & $\begin{array}{l}\text { He moves the 'wrong' image away from the dock } \\
\text { zone, prior to making his second selection. }\end{array}$ \\
\hline $\begin{array}{l}\text { Child D. He does not like computers. He does like } \\
\text { repetitive, interactive stories. He is unable to } \\
\text { understand emotions or motives, and is unable to } \\
\text { tell stories as he has with little productive language. }\end{array}$ & $\begin{array}{l}\text { When first seen he did not attempt to dock any } \\
\text { t-story images, moving images in a seemingly } \\
\text { random manner. By visit } 7 \text { he was docking an } \\
\text { image for every t-story offered; the number } \\
\text { t-stories for which he docked an image over the } \\
\text { first } 7 \text { visits were } \\
\text { [not present, } 0,3,13,12,15,16] \text {. He rarely selects the } \\
\text { leftmost image. }\end{array}$ & $\begin{array}{l}\text { By visit } 7 \text {, after docking a wrong image, this child } \\
\text { leaves it in place, and moves the other two images } \\
\text { to the upper half of the screen, covering other } \\
\text { images in the t-story, thus creating the effect of Fig } \\
4 \text {. }\end{array}$ \\
\hline $\begin{array}{l}\text { Child } J \text { is fascinated by words. He like computers } \\
\text { and repetitive stories. He may understand basic } \\
\text { emotions such as happy and sad. He does not tell } \\
\text { stories. He 'blocks out' adults by singing or reciting. } \\
\text { He needs to constantly be re-focussed on the set } \\
\text { task. }\end{array}$ & $\begin{array}{l}\text { On visit } 3 \text { (the first on which he saw TouchStory) } \\
\text { he selected the middle image first on } 12 \text { out of } \\
16 . \text { occasions. He self corrected on } 2 \text { occasions. On } \\
\text { subsequent visits he selected the middle image first } \\
\text { in every instance. }\end{array}$ & $\begin{array}{l}\text { On visit } 3 \text { he chose another image on } 6 \text { occasions, } \\
\text { and moved straight on to the next t-story on } 3 \\
\text { occasions. By visit } 7 \text { always moves straight on to } \\
\text { the next t-story }\end{array}$ \\
\hline
\end{tabular}

TABLE 2

THE NUMBER OF T-STORIES ANSWERED CORRECTLY BY EACH CHILD AT EACH VISIT $(*$ DENOTES THE CHILD WAS NOT PRESENT; FOR EACH VISIT THE NUMBER OF T-STORIES PRESENTED IS SHOWN IN BRACKETS).

\begin{tabular}{|l|r|r|r|r|r|r|r|}
\hline CHILD & $\begin{array}{c}\text { visit 1 } \\
(14)\end{array}$ & $\begin{array}{l}\text { visit 2 } \\
(14)\end{array}$ & $\begin{array}{l}\text { visit 3 } \\
\text { (16) }\end{array}$ & $\begin{array}{l}\text { visit 4 } \\
(16)\end{array}$ & $\begin{array}{l}\text { visit 5 } \\
(16)\end{array}$ & $\begin{array}{l}\text { visit 6 } \\
\text { (16) }\end{array}$ & $\begin{array}{l}\text { visit 7 } \\
(16)\end{array}$ \\
\hline $\mathrm{C}$ & 9 & 10 & 11 & 14 & 12 & 14 & 16 \\
\hline $\mathrm{E}$ & 7 & 6 & 5 & 6 & 6 & 10 & 8 \\
\hline $\mathrm{H}$ & 12 & 14 & 15 & 15 & 13 & 15 & 15 \\
\hline $\mathrm{N}$ & 11 & 12 & 13 & 13 & 13 & 13 & 14 \\
\hline $\mathrm{D}$ & $*$ & 0 & 3 & 2 & 3 & 4 & 6 \\
\hline $\mathrm{J}$ & $*$ & $*$ & 6 & 9 & 7 & 7 & 7 \\
\hline
\end{tabular}

Child D, who does not like computers, would, by visit 7 , engage with TouchStory sufficiently to dock an image for every t-story presented to him. When he docked a wrong option, he then manually created the effect of the 'right answer' feedback, as shown in Fig 4, by moving remaining images to the top part of the screen. Whether he has any appreciation of the meaning of the feedback from TouchStory is not known. He may have been responding to positive encouragement from the attending adult when an answer is correct, and consider that effect in itself as the required goal.

Last, we consider Child J. On his first exposure to TouchStory he both actively chose images, and would try again if he selected a wrong image. However recall that the end of the game is signalled by a screen showing the words 'Thank You'. This child currently had a fascination with words. He reacted strongly to the 'Thank you' screen and on visit 7 could be heard chanting 'than-kyuo' (emphasis as shown) both in anticipation of, and after his TouchStory sessions. He did not actively engage at either of the choice points, he rushed the t-stories in order to get to the greater reward of the word on the screen. This underlines the point that every decision may have unanticipated consequences when designing software for children with autism. 


\section{CONCLUSIONS AND FUTURE WORK}

The contexts: The results obtained allow some reflection regarding the specificities of the development of TouchStory in particular and software for children with autism in general. $\mathrm{Du}$ Boulay discusses a set of generic challenges that researchers involved in the creation of educational software face and he raises a number of questions in [20] from which we select the following as particularly relevant to this study: "How can we engage and motivate so they(students) are willing to attempt to learn? How can we detect what the goals of the student are (if any)? How to maintain focus and coherence in the interaction? How to make the teacher's intentions to the learner clear? What makes an environment educationally rich? How does one choose what assistance might be helpful?" These are all difficult questions whoever the learner, but doubly so in the case of children with autism.

How can we engage and motivate so they are willing to attempt to learn? TouchStory, presented via a touch screen, does engage all of the children in the sense that they are all keen to attend their session. In some cases the design issues may be considered effective, the children appear to reason, reflect, and improve. We also observe that some of the children monitor their responses, 'changing their mind' in a seemingly purposeful way about their choice of option, and varying their response strategy according to the t-story. Child $H$ shows this clearly. In the cases of Child $\mathbf{J}$ and Child D, while participating, they do not use TouchStory as intended.

How can we detect what the goals of the student are (if any)? Although few of the children speak about their goals in any way, it seems clear that success with TouchStory is important to some of them. We see that a number of them make positive choices, and learn from trial and error. In the case of Child $\mathrm{J}$ the unintended goal is abundantly explicit. The difficulty lies in detecting less obvious unexpected goals.

How to maintain focus and coherence in the interaction? The simplicity of TouchStory and the nature of autism mean that once focus is obtained it is not generally lost. In the case of Child $\mathrm{J}$ we are not able to distract him from his own goal, so focus in never established. It is our strong belief that any measures introduced to re-establish focus must be wholly task related.

How to make the teacher's intentions to the learner clear? The technique used was verbal explanation accompanied by physical demonstration. This was successful for 5 of the participants. It is probable that Child D did not understand our intentions; in further work we will consider the possibility of providing more explicit feedback, which might guide Child D, while retaining the current simplicity of TouchStory. Experience with Child J, who did understand the task and feedback at the first visit, re-enforces our view that attempts to convey information, to engage and motivate the child, and to maintain focus and to render assistance, must all be directly relevant to learning task.

What makes an environment educationally rich? Can all of the above questions be somehow incorporated in the software itself and provide support for reflection and reasoning? How can the questions themselves be adapted to each child's needs? Experience with Child D, shows that positive feedback might be recognised without its significance being necessarily recognised. Can this issue be improved? What design techniques are appropriate?

Difficulties of interpretation: The present study supports our belief that careful observation of behaviour gives us some insight into the autistic child's goals and understanding. However, the interpretation is not easy; we do not know the basis of the child choice of image or strategy. For a typical learner these questions may be answered by questioning or inspection of verbal or written self monitoring, for learners with autism this remains an open question.

\section{REFERENCES}

[1] J. Bruner, "The Narrative Construction of Reality," Critical Inquiry, vol. 18, pp. 1-21, 1991.

[2] K. Dautenhahn, "The Origins of Narrative: In Search for the Transactional Format of Narratives in Humans and Other Social Animals." International Journal of Cognition and Technology: Coexistence, Convergence, Co-evolution, vol. 1, pp. 97-123, 2002.

[3] L. Capps, M. Losh, and C. Thurber, "The Frog Ate the Bug and Made his Mouth Sad; Narrative Competence in Children with Autism," Journal of Abnormal Child Psychology, vol. 18, pp. 193-204, 2000.

[4] O. Sacks, An Anthropologist on Mars: Picador, 1996.

[5] H. Tager-Flushberg and K. Sullivan, "Attributing mental states to story characters: A comparison of narratives produced by autistic and mentally retarded individuals." Applied Psycholinguistics, vol. 16, pp. 241-256, 1995

[6] M. Davis, K. Dautenhahn, C. L. Nehaniv, and S. D. Powell, "The narrative construction of our (social) world: steps towards an interactive learning environment for children with autism," Journal of Universal Access in the Information Society., in press.

[7] D. Murray, "Autism and Information Technology: Therapy with Computers," in Autism and Learning: a guide to good practice, S. Powell and R. Jordan, Eds. London: David Foulton, 1997.

[8] A. Tartaro and J. Cassell, "Authorable Virtual Peers for Autistic Spectrum Disorders," presented at 17th European Conference on Artificial Intelligence (ECAI06) Riva del Garda, Italy.

[9] D. W. Massaro, "Embodied Agents in Language Learning for Children with Language Challenges," presented at ICCHP, Linz, Austria, 2006...

[10] U. Frith, Explaining the Enigma: Blackwells, 1989.

[11] S. D. Powell, "Autism," in Developmental Psychology, D. J. Messer, Millar, S., Ed. Cambridge: Cambridge, 1999, pp. 243-261.

[12] L. Wing, The Autistic Spectrum: A Guide for Parents and Professionals. London: Constable, 1996.

[13] O. Bogdashina, " A Reconstruction of the Sensory World of Autism," Proceedings of the 7th International Autism-Europe Congress, 2003.

[14] NAS, "National Autistic Society," National Autistic Society.

[15] T. Grandin, Thinking in Pictures. New York: Doubleday, 1995.

[16] R. Jordan and S. D. Powell, Understanding and Teaching Children with Autism: John Wiley and Sons, 1995.

[17] F. Happé, "Central coherence and theory of mind in autism: Reading homographs in context.," British Journal of Developmental Psychology, vol. 15, pp. 1-12, 1997.

[18] L. Steels, "The Architecture of Flow," in A Learning Zone of One's Own, M. Tokoro and L. Steels, Eds.: IOS press, 2004.

[19] A. C. Graesser, Wienner-Hastings, K, "Situation Models and Concepts in Story Comprehension," in Narrative Comprehension, Causality and Coherence., S. Goldman, Graesser, A.C., van den Broek, P., Ed.: LEA, 1999

[20] B. du Boulay, "Fallible, Distractible, Forgetful, Wilfull and Irrational Learners," in Computers as Cognitive Tools: Volume II ; No More Walls, S. P. Lajoie, Ed.: LEA, 2000, pp. 339-376. 